\title{
Atributos físicos de Latossolos adubados durante cinco anos com biossólido
}

\author{
Valéria Peruca de Melo(1), Amauri Nelson Beutler(2), Zigomar Menezes de Souza(2), \\ José Frederico Centurion ${ }^{(3)}$ e Wanderley José de Melo ${ }^{(4)}$
}

\begin{abstract}
(1)Universidade Estadual Paulista (Unesp), Fac. de Ciências Agrárias e Veterinárias (FCAV), Dep. de Tecnologia, Via de acesso Prof. Paulo Donato Castellane, s/n, CEP 14884-900 Jaboticabal, SP. Bolsista da Capes. E-mail: vpmelo@bol.com.br (2)Unesp, FCAV, Dep. de Solos e Adubos. Bolsista da Fapesp. E-mail: amaurib@yahoo.com.br, zigomar@fcav.unesp.br (3)Unesp, FCAV, Dep. de Solos e Adubos. Bolsista do CNPq. E-mail: jfcentur@fcav.unesp.br (4)Unesp, FCAV, Dep. de Tecnologia. Bolsista do CNPq. E-mail: wjmelo@fcav.unesp.br
\end{abstract}

\begin{abstract}
Resumo - A utilização do biossólido para fins agrícolas tem sido uma alternativa viável para resíduos de origem domiciliar e industrial. O objetivo deste trabalho foi avaliar o efeito da aplicação de biossólido nos atributos físicos de Latossolo Vermelho distrófico, textura média (LVd), e Latossolo Vermelho eutroférrico argiloso (LVef). Utilizaram-se as doses, acumuladas em 5 anos, de 0,0, 25,0, 47,5 e 50,0 $\mathrm{Mg} \mathrm{ha}^{-1}$ de matéria seca de biossólido, incorporadas até $0,1 \mathrm{~m}$ com grade. As amostras deformadas foram coletadas no quinto ano, após a colheita do milho, nas camadas de $0,0-0,1$, de $0,1-0,2$ e de $0,2-0,3 \mathrm{~m}$ para determinação da composição granulométrica e matéria orgânica. As amostras indeformadas coletadas com cilindros metálicos de $0,030 \mathrm{~m}$ de altura e $0,048 \mathrm{~m}$ de diâmetro, também no quinto ano, foram utilizadas para determinação da densidade, porosidade e retenção de água no solo. A macroporosidade foi superior a partir de 47,5 $\mathrm{Mg} \mathrm{ha}^{-1}$ e 50,0 $\mathrm{Mg} \mathrm{ha}^{-1}$ de biossólido, no LVd e LVef, respectivamente, e a densidade do solo foi inferior na dose de $50,0 \mathrm{Mg} \mathrm{ha}^{-1}$ no LVd de textura média, na camada de $0,0-0,1 \mathrm{~m}$. A aplicação de 50,0 $\mathrm{Mg} \mathrm{ha}^{-1}$ de biossólido não alterou a porosidade total, a microporosidade e a retenção de água nos dois solos. O efeito da aplicação do biossólido depende do tipo de solo e da quantidade aplicada.
\end{abstract}

Termos para indexação: porosidade do solo, densidade do solo, retenção de água, lodo de esgoto.

\section{Physical attributes of Oxisols fertilized along five years with biosolids}

\begin{abstract}
The use of biosolids in agriculture has been the most viable alternative for domestic and industrial residues. The objective of this study was to evaluate the effect of biosolids addition on physical attributes of an Oxisol medium texture (LVd) and an Oxisol clayey (LVef). Accumulated doses of biosolids of 0.0, 25.0, 47.5, $50.0 \mathrm{Mg} \mathrm{ha}^{-1}$ were incorporated at $0.1 \mathrm{~m}$ depth. Deformed samples were collected in the fifth year after maize harvest, at the depths of $0.0-0.1,0.1-0.2$ and $0.2-0.3 \mathrm{~m}$ for the determination of granulometric composition and organic matter. Undeformed samples were collected with metallic cylinders of $0.03 \mathrm{~m}$ of height and $0.048 \mathrm{~m}$ diameter were taken for determination of bulk density, porosity and water retention in soil. The macroporosity increased at $47.5 \mathrm{Mg} \mathrm{ha}^{-1}$ and $50.0 \mathrm{Mg} \mathrm{ha}^{-1}$ of biosolids, in LVd and LVef, respectively, and the soil bulk density decreased at $50.0 \mathrm{Mg} \mathrm{ha}^{-1}$ in LVd, at the depth of $0.0-0.1 \mathrm{~m}$. The application of $50.0 \mathrm{Mg} \mathrm{ha}^{-1}$ biosolids did not modify total porosity, microporosity and water retention in all tensions, in both soils. The effect of the application of biosolids depends on the soil type and de amount applied.
\end{abstract}

Index terms: soil pore system, soil density, water retention, sewage sludge.

\section{Introdução}

Os resíduos sólidos de origem domiciliar e industrial são um dos grandes problemas ambientais na atualidade, sendo os resíduos de esgoto os mais problemáticos (Alves et al., 1999). Após tratados biologicamente, os esgotos produzem um resíduo rico em matéria orgânica chamado de biossólido, que varia de $40 \%$ a $60 \%$. Entre as alternativas para a destinação final do biossólido pode-se citar seu uso na produção de energia (Goldstein et al., 1998). A utilização agronômica, no entanto, apresenta maior potencial, e oferece a oportunidade de seu uso como fertilizante e condicionador de solos (Silva et al., 2002). O biossólido tem sido utilizado na melhoria de áreas florestadas, na recuperação de áreas degradadas, como fertilizante em culturas anuais de grãos e condicionador físico do solo (Silva et al., 1997; Sloan et al., 1997). No entanto, atualmente existe a tendência 
de utilização de altas doses de biossólido, que podem contaminar o solo com metais pesados (Sloan et al., 1997; Melo et al., 2001) e patógenos (Jofre, 1997).

Em relação aos atributos físicos, a aplicação de lodo de esgoto promove aumento na porosidade total e macroporosidade (Ortega et al., 1981; Pagliai et al., 1981; Mathan, 1994), diminuição na densidade do solo (Aggelides \& Londra, 2000) e maior retenção de água (Kumar et al., 1985; Aggelides \& Londra, 2000; Debosz et al., 2002).

Jorge et al. (1991), estudando a adição de $10,0 \mathrm{Mg} \mathrm{ha}^{-1} \mathrm{ano}^{-1}$ de lodo de esgoto em Latossolo Vermelho argiloso, não verificaram alterações na retenção de água nas tensões de 0,03 e $0,1 \mathrm{MPa}$, mas verificaram alterações na relação macro e microporos sem, no entanto, alterações significativas na porosidade total e densidade do solo.

Quanto à transmissão de água no solo, a matéria orgânica tem efeitos indiretos, atuando tanto no aumento da agregação e da porosidade quanto na diminuição da densidade do solo (Metzger \& Yaron, 1987). Beutler et al. (2002) verificaram que pequenas variações no teor de matéria orgânica não alteraram a retenção de água, que foi maior com o aumento da densidade do solo, nas tensões de água de 0,006 a 0,3 MPa. A retenção de água do solo é característica específica de cada solo, sendo resultado da ação conjunta e complexa de vários fatores, como o teor e mineralogia da fração argila (Ferreira et al., 1999), teor de matéria orgânica, estrutura (Reichardt, 1988) e densidade do solo (Beutler et al., 2002).

Segundo Marciano et al. (2001), quando o solo originalmente possui uma boa estrutura, podem não ocorrer melhorias nos atributos físicos, mesmo com a aplicação de grandes quantidades de biossólido, principalmente em propriedades com grande variabilidade espacial, como as de transmissão de água no solo. Furrer \& Stauffer (1983) não verificaram alterações na estabilidade de agregados com a aplicação de lodo de esgoto em solos bem estruturados e argilosos. Logan et al. (1996) verificaram que a aplicação de grandes quantidades de lodo de esgoto não alteraram as propriedades que influenciam a transmissão de água no solo, independentemente da textura.

O objetivo deste trabalho foi avaliar o efeito da aplicação de biossólido em atributos físicos de dois Latossolos.

\section{Material e Métodos}

O trabalho foi realizado em um Latossolo Vermelho distrófico típico, textura média, A moderado caulinítico (LVd) e em Latossolo Vermelho eutroférrico típico, textura argilosa, A moderado caulinítico-oxídico (LVef), localizados na fazenda de ensino e pesquisa da Faculdade de Ciências Agrárias e Veterinárias da Unesp de Jaboticabal, SP. As coordenadas geográficas da área são de $21^{\circ} 4^{\prime}$ a $21^{\circ} 21^{\prime}$ Sul e $48^{\circ} 8^{\prime}$ a $48^{\circ} 26^{\prime}$ Oeste. O clima é o mesotérmico de inverno seco (Cwa), pelo critério de classificação climática de Köppen. A caracterização granulométrica dos solos é apresentada na Tabela 1.

Utilizaram-se as seguintes doses acumuladas de matéria seca de biossólido, obtido na Estação de Tratamento de Esgoto (ETE) da cidade de Barueri, SP, administrada pela SABESP: 0,0, 25,0, 47,5 e 50,0 $\mathrm{Mg} \mathrm{ha}^{-1}$, aplicadas manualmente na superfície e incorporadas até $0,1 \mathrm{~m}$ de profundidade com grade, antes da semeadura do milho. No tratamento de 25,0 e $50,0 \mathrm{Mg} \mathrm{ha}^{-1}$, foram aplicados 5,0 e 10,0 $\mathrm{Mg} \mathrm{ha}^{-1}$ ano $^{-1}$ de biossólido e no tratamento de 47,5 $\mathrm{Mg} \mathrm{ha}^{-1}$, foram aplicados $2,5 \mathrm{Mg} \mathrm{ha}^{-1}$, durante três anos, e $20,0 \mathrm{Mg} \mathrm{ha}^{-1}$ nos dois últimos anos. O biossólido apresentou a seguinte composição química média: C orgânico, 347,83 $\mathrm{g} \mathrm{kg}^{-1}$; N, 36,54 $\mathrm{g} \mathrm{kg}^{-1}$; $\mathrm{P}, 17,15 \mathrm{~g} \mathrm{~kg}^{-1} ; \mathrm{K}, 1,62 \mathrm{~g} \mathrm{~kg}^{-1}$; $\mathrm{Ca}, 26,95 \mathrm{~g} \mathrm{~kg}^{-1} ; \mathrm{Mg}$, $3,68 \mathrm{~g} \mathrm{~kg}^{-1}$; Mn, 248,29 mg kg-1; Fe, 20.294,45 mg kg-1; $\mathrm{Zn}, 2.716,96 \mathrm{mg} \mathrm{kg}^{-1} \mathrm{e} \mathrm{Pb}, 219,00 \mathrm{mg} \mathrm{kg}^{-1}$. Utilizou-se o delineamento experimental em blocos casualizados com quatro doses de biossólido e cinco repetições, tendo cada parcela $54 \mathrm{~m}^{2}$.

Tabela 1. Valores médios $(\mathrm{n}=5)$ da composição granulométrica $\left(\mathrm{g} \mathrm{kg}^{-1}\right)$ em diferentes camadas de Latossolo Vermelho distrófico, textura média (LVd), e Latossolo Vermelho eutroférrico argiloso (LVef).

\begin{tabular}{|c|c|c|c|c|c|c|}
\hline \multirow[t]{3}{*}{ Fração } & \multicolumn{3}{|c|}{ Latossolo Vermelho distrófico } & \multicolumn{3}{|c|}{ Latossolo Vermelho eutroférrico argiloso } \\
\hline & $0,0-0,1$ & $0,1-0,2$ & $0,2-0,3$ & $0,0-0,1$ & $0,1-0,2$ & $0,2-0,3$ \\
\hline & ------- & $----(m)--$ & - - & ------ & $---(m)-$ & \\
\hline Argila & 245 & 278 & 285 & 485 & 508 & 525 \\
\hline Silte & 68 & 62 & 63 & 297 & 281 & 273 \\
\hline Areia total & 687 & 661 & 652 & 219 & 212 & 202 \\
\hline Areia grossa & 388 & 349 & 356 & 90 & 86 & 77 \\
\hline Areia fina & 299 & 312 & 296 & 129 & 126 & 125 \\
\hline
\end{tabular}


O milho (Zea mays cv. Agromen 3150) foi semeado, anualmente, no espaçamento de $0,9 \mathrm{~m}$, com 5 sementes por metro linear, perfazendo 55.500 plantas ha $^{-1}$, sendo adubado com $150 \mathrm{~kg} \mathrm{ha}^{-1}$ de sulfato de amônio, $278 \mathrm{~kg} \mathrm{ha}^{-1}$ de superfosfato simples, e 86,2 $\mathrm{kg} \mathrm{ha}^{-1} \mathrm{de}$ cloreto de potássio, de acordo com a recomendação para a cultura. O controle de invasoras foi realizado com herbicidas.

As amostras de solo foram coletadas em abril de 2002, no quinto ano de condução do experimento, após a colheita de milho, nas camadas de $0,0-0,1,0,1-0,2$ e $0,2-0,3 \mathrm{~m}$ de profundidade, com uma repetição por parcela. As amostras deformadas foram passadas em peneira de malha $2 \mathrm{~mm}$ para determinação da composição granulométrica através da dispersão com água e $\mathrm{NaOH}$ $\left(0,1 \mathrm{~mol} \mathrm{~L}^{-1}\right)$ e agitação lenta (16 horas), sendo a argila obtida pelo método da pipeta, segundo Embrapa (1997). O C orgânico foi obtido por oxidação (Embrapa, 1997) e a matéria orgânica, multiplicando-se o C orgânico por 1,724 . Nas amostras indeformadas, coletadas com auxílio de anéis volumétricos de $0,048 \mathrm{~m}$ de diâmetro e $0,030 \mathrm{~m}$ de altura, determinaram-se a retenção de água, por secamento, nas tensões de $0,001,0,006,0,01,0,033$, 0,06, 0,1 e 0,3 MPa, em câmaras de pressão de Richards com placa porosa (Klute, 1986). As curvas de retenção de água foram ajustadas, segundo modelo matemático proposto por Genuchten (1980), sendo a retenção de água a 1,5 MPa estimada por meio do modelo. Considerando-se os dados de retenção de água ajustados, foram obtidas a porosidade total, segundo Danielson \& Sutherland (1986), e a microporosidade, correspondente à umidade de tensão $0,006 \mathrm{MPa}$. A macroporosidade foi obtida pela diferença entre a porosidade total e a microporosidade. A densidade do solo foi determinada segundo Blake \& Hartge (1986). Os dados foram submetidos à análise de variância e as médias comparadas pelo teste de Tukey a 5\% de probabilidade.

\section{Resultados e Discussão}

No LVd e LVef, na camada de $0,0-0,1 \mathrm{~m}$, os teores de matéria orgânica foram superiores, coerentes com a adição de biossólido, que foi incorporado com grade nesta camada (Tabela 2). Navas et al. (1998) também verificaram maior teor de matéria orgânica com a aplicação de 40,0 $\mathrm{Mg} \mathrm{ha}^{-1}$ de massa seca de lodo de esgoto com $73 \%$ de matéria orgânica.

$\mathrm{O}$ teor de matéria orgânica determinado no quinto ano foi superior a partir da aplicação de $25,0 \mathrm{Mg} \mathrm{ha}^{-1} \mathrm{de}$ biossólido, na camada de $0,0-0,1 \mathrm{~m}$, nos dois solos. Melo (2002) não verificou diferenças significativas após três anos de aplicação das mesmas doses de biossólido. Neste sentido, Gonçalves \& Ceretta (1999) afirmaram que, em solos tropicais, é difícil obter aumentos significativos nos teores de matéria orgânica em curto espaço de tempo. Nas camadas de $0,1-0,2$ e $0,2-0,3$ m, não houve diferença nos teores de matéria orgânica entre tratamentos e camadas.

A porosidade total e a microporosidade não diferiram entre as camadas e doses de biossólido nos dois solos (Tabela 3). Furrer \& Stauffer (1983) afirmaram que a adição de lodo de esgoto pode não alterar a porosidade total, independentemente da condição original do solo. Por sua vez, Navas et al. (1998) obtiveram incremento da porosidade total de $0,38 \mathrm{~m}^{3} \mathrm{~m}^{-3}$ para $0,49 \mathrm{~m}^{3} \mathrm{~m}^{-3}$, quando foram aplicados $320 \mathrm{Mg} \mathrm{ha}^{-1}$ de lodo de esgoto. Em relação à microporosidade, Jorge et al. (1991) também não encontraram diferenças na microporosidade com a aplicação de 20,0 $\mathrm{Mg} \mathrm{ha}^{-1}$ ano $^{-1}$ de lodo de esgoto, durante quatro anos, em Latossolo Vermelho argiloso. Sort \& Alcañiz (1999) verificaram que a aplicação de $400 \mathrm{Mg} \mathrm{ha}^{-1}$, em quatro anos, não alterou a microporosidade ao final deste período.

A macroporosidade apresentou valores superiores a partir de 47,5 $\mathrm{Mg} \mathrm{ha}^{-1}$ e 50,0 $\mathrm{Mg} \mathrm{ha}^{-1}$ no LVd e LVef, respectivamente, e apenas na camada de $0,0-0,1 \mathrm{~m}$

Tabela 2. Valores médios $(\mathrm{n}=5)$ de matéria orgânica $\left(\mathrm{g} \mathrm{kg}^{-1}\right)$ em diferentes doses de biossólido e camadas de Latossolo Vermelho distrófico, textura média (LVd), e Latossolo Vermelho eutroférrico argiloso (LVef) ${ }^{(1)}$.

\begin{tabular}{|c|c|c|c|c|c|c|}
\hline \multirow{2}{*}{$\begin{array}{l}\text { Dose de } \\
\text { biossólido } \\
\left(\mathrm{Mg} \mathrm{ha}^{-1}\right)\end{array}$} & \multicolumn{3}{|c|}{ Latossolo Vermelho distrófico } & \multicolumn{3}{|c|}{ Latossolo Vermelho eutroférrico argiloso } \\
\hline & $0,0-0,1$ & $0,1-0,2$ & $0,2-0,3$ & $0,0-0,1$ & $0,1-0,2$ & $0,2-0,3$ \\
\hline 0,0 & $16,60 \mathrm{Ca}$ & $13,40 \mathrm{Ab}$ & $11,20 \mathrm{Ab}$ & $28,40 \mathrm{Ca}$ & $21,00 \mathrm{Ab}$ & $18,80 \mathrm{Ab}$ \\
\hline 25,0 & $20,40 \mathrm{Ba}$ & $13,20 \mathrm{Ab}$ & $11,00 \mathrm{Ab}$ & $31,00 \mathrm{Ba}$ & $22,00 \mathrm{Ab}$ & $20,40 \mathrm{Ab}$ \\
\hline 47,5 & $27,00 \mathrm{Aa}$ & $12,80 \mathrm{Ab}$ & $10,80 \mathrm{Ab}$ & $38,00 \mathrm{Aa}$ & $21,20 \mathrm{Ab}$ & $19,00 \mathrm{Ab}$ \\
\hline 50,0 & $26,40 \mathrm{Aa}$ & $13,20 \mathrm{Ab}$ & $11,40 \mathrm{Ab}$ & $36,60 \mathrm{Aa}$ & $22,40 \mathrm{Ab}$ & $20,40 \mathrm{Ab}$ \\
\hline
\end{tabular}

${ }^{(1)}$ Médias seguidas da mesma letra, maiúscula na coluna e minúscula na linha, para a mesma variável e solo, não diferem entre si, a 5\% de probabilidade, pelo teste de Tukey; os coeficientes de variação foram de 9,38\% e 8,28\%, em relação aos solos LVd e LVef, respectivamente. 
(Tabela 3). Nesse sentido, Bertol (1989) afirmou que os macroporos são os primeiros e mais afetados pelo processo de compactação. Este pesquisador verificou que, com o aumento da densidade nos sistemas de uso do solo, ocorreu redução da macroporosidade, em todas as camadas analisadas, comparado à condição natural.

Valores superiores de macroporosidade, sem alterar a microporosidade, em Latossolo Vermelho argiloso, também foram verificados no quarto ano por Jorge et al. (1991), com a aplicação de $10,0 \mathrm{Mg} \mathrm{ha}^{-1}$ ano $^{-1}$ de lodo de esgoto e, com redução da microporosidade na dose de 20,0 $\mathrm{Mg} \mathrm{ha}^{-1}$ ano $^{-1}$.

A densidade do solo diminui significativamente apenas na dose de 50,0 $\mathrm{Mg} \mathrm{ha}^{-1}$ de biossólido no LVd (Tabela 3), na camada de 0,0-0,1 m. Navas et al. (1998) também observaram que a aplicação de $40,0 \mathrm{Mg} \mathrm{ha}^{-1}$ de lodo de esgoto em um solo de textura média promoveu redução da densidade do solo, e Lindsay \& Logan (1998) verificaram que a aplicação de $60 \mathrm{Mg} \mathrm{ha}^{-1}$, em quatro anos, promoveu redução da densidade do solo no último ano.
No LVef não foram observadas alterações na densidade do solo com a adição de até $50,0 \mathrm{Mg} \mathrm{ha}^{-1}$, possivelmente, segundo Ferreira et al. (1999), por causa da mineralogia oxídica que confere ao solo uma melhor estrutura natural em relação ao $\mathrm{LVd}$, de textura mais grosseira e com mineralogia caulinítica, em que a matéria orgânica adicionada pelo biossólido promove maiores efeitos no aumento da agregação e volume do solo; Jorge et al. (1991) também não verificaram alterações na densidade do solo após a adição de $80,0 \mathrm{Mg} \mathrm{ha}^{-1}$ de lodo de esgoto, em quatro anos, em Latossolo Vermelho argiloso.

Os resultados obtidos mostram que os efeitos da aplicação do biossólido na redução da densidade do solo depende do tipo de solo e da quantidade aplicada. Nesse contexto, Aggelides \& Londra (2000) concluíram que a aplicação de $75,0 \mathrm{Mg} \mathrm{ha}^{-1}$ de uma mistura de $62 \%$ de lixo doméstico, $21 \%$ de lodo de esgoto e $17 \%$ de serragem, até $0,15 \mathrm{~m}$ de profundidade, promoveu redução na densidade do solo de 1,37 para 1,20 e de 1,12 para 1,05 em solo de textura média e argilosa, respectivamente;

Tabela 3. Valores médios $(n=5)$ de porosidade total, macro e microporosidade e densidade do solo em diferentes doses de biossólido e camadas de Latossolo Vermelho distrófico, textura média (LVd), e Latossolo Vermelho eutroférrico argiloso (LVef) ${ }^{(1)}$.

\begin{tabular}{llccccc}
\hline $\begin{array}{l}\text { Dose de } \\
\text { biossólido } \\
\left(\mathrm{Mg} \mathrm{ha}^{-1}\right)\end{array}$ & $0,0-0,1$ & $0,1-0,2$ & & & \multicolumn{2}{c}{ Latossolo Vermelho eutroférrico argiloso } \\
\cline { 2 - 3 } & - & $0,2-0,3$ & & $0,0-0,1$ & $0,1-0,2$ & $0,2-0,3$ \\
\hline
\end{tabular}

\begin{tabular}{|c|c|c|c|c|c|c|}
\hline \multicolumn{7}{|c|}{ Porosidade total $\left(\mathrm{m}^{3} \mathrm{~m}^{-3}\right)$} \\
\hline 0,0 & $0,362 \mathrm{Aa}$ & $0,364 \mathrm{Aa}$ & $0,358 \mathrm{Aa}$ & $0,517 \mathrm{Aa}$ & $0,516 \mathrm{Aa}$ & $0,517 \mathrm{Aa}$ \\
\hline 25,0 & $0,367 \mathrm{Aa}$ & $0,365 \mathrm{Aa}$ & $0,358 \mathrm{Aa}$ & $0,516 \mathrm{Aa}$ & $0,505 \mathrm{Aa}$ & $0,508 \mathrm{Aa}$ \\
\hline 47,5 & $0,366 \mathrm{Aa}$ & $0,363 \mathrm{Aa}$ & $0,369 \mathrm{Aa}$ & $0,526 \mathrm{Aa}$ & $0,513 \mathrm{Aa}$ & $0,511 \mathrm{Aa}$ \\
\hline 50,0 & $0,372 \mathrm{Aa}$ & $0,365 \mathrm{Aa}$ & $0,362 \mathrm{Ab}$ & $0,525 \mathrm{Aa}$ & $0,507 \mathrm{Aa}$ & $0,514 \mathrm{Aa}$ \\
\hline \multicolumn{7}{|c|}{ Macroporosidade $\left(\mathrm{m}^{3} \mathrm{~m}^{-3}\right)$} \\
\hline 0,0 & $0,091 \mathrm{Ba}$ & $0,086 \mathrm{Aa}$ & $0,088 \mathrm{Aa}$ & $0,140 \mathrm{Ba}$ & $0,093 \mathrm{Ab}$ & $0,129 \mathrm{Aa}$ \\
\hline 25,0 & $0,095 \mathrm{Ba}$ & $0,094 \mathrm{Aa}$ & $0,093 \mathrm{Aa}$ & $0,147 \mathrm{ABa}$ & $0,091 \mathrm{Ab}$ & $0,129 \mathrm{Aa}$ \\
\hline 47,5 & $0,100 \mathrm{Aa}$ & $0,091 \mathrm{Ab}$ & $0,099 \mathrm{Aa}$ & $0,154 \mathrm{ABa}$ & $0,095 \mathrm{Ac}$ & $0,127 \mathrm{Ab}$ \\
\hline 50,0 & $0,111 \mathrm{Aa}$ & $0,094 \mathrm{Ab}$ & $0,095 \mathrm{Ab}$ & $0,161 \mathrm{Aa}$ & $0,089 \mathrm{Ac}$ & $0,123 \mathrm{Ab}$ \\
\hline \multicolumn{7}{|c|}{ Microporosidade $\left(\mathrm{m}^{3} \mathrm{~m}^{-3}\right)$} \\
\hline 0,0 & $0,271 \mathrm{Aa}$ & $0,278 \mathrm{Aa}$ & $0,270 \mathrm{Aa}$ & $0,367 \mathrm{Aa}$ & $0,422 \mathrm{Aa}$ & $0,387 \mathrm{Aa}$ \\
\hline 25,0 & $0,273 \mathrm{Aa}$ & $0,280 \mathrm{Aa}$ & $0,265 \mathrm{Aa}$ & $0,369 \mathrm{Aa}$ & $0,414 \mathrm{Aa}$ & 0,379Aa \\
\hline 47,5 & $0,266 \mathrm{Aa}$ & $0,272 \mathrm{Aa}$ & $0,271 \mathrm{Aa}$ & $0,372 \mathrm{Aa}$ & $0,418 \mathrm{Aa}$ & $0,383 \mathrm{Aa}$ \\
\hline 50,0 & $0,261 \mathrm{Aa}$ & $0,271 \mathrm{Aa}$ & $0,270 \mathrm{Aa}$ & $0,364 \mathrm{Aa}$ & $0,419 \mathrm{Aa}$ & $0,391 \mathrm{Aa}$ \\
\hline \multicolumn{7}{|c|}{ Densidade do solo $\left(\mathrm{Mg} \mathrm{m}^{-3}\right)$} \\
\hline 0,0 & $1,57 \mathrm{Aa}$ & $1,59 \mathrm{Aa}$ & $1,55 \mathrm{Aa}$ & $1,24 \mathrm{Aa}$ & 1,31Aa & $1,27 \mathrm{Aa}$ \\
\hline 25,0 & $1,55 \mathrm{Aa}$ & $1,57 \mathrm{Aa}$ & $1,55 \mathrm{Aa}$ & $1,20 \mathrm{Aa}$ & $1,32 \mathrm{Aa}$ & $1,28 \mathrm{Aa}$ \\
\hline 47,5 & $1,50 \mathrm{ABa}$ & $1,57 \mathrm{Aa}$ & $1,54 \mathrm{Aa}$ & $1,18 \mathrm{Aa}$ & $1,32 \mathrm{Aa}$ & $1,27 \mathrm{Aa}$ \\
\hline 50,0 & $1,45 \mathrm{Bb}$ & $1,57 \mathrm{Aa}$ & $1,54 \mathrm{Aa}$ & $1,14 \mathrm{Aa}$ & $1,31 \mathrm{Aa}$ & $1,27 \mathrm{Aa}$ \\
\hline
\end{tabular}

(1) Médias seguidas da mesma letra, maiúscula na coluna e minúscula na linha, para a mesma a variável e solo, não diferem entre si, a 5\% de probabilidade, pelo teste de Tukey. 
Logan et al. (1996) verificaram redução da densidade de um solo de textura média com a aplicação de elevadas doses de lodo de esgoto.

Não foram observadas diferenças na retenção de água, em todas as tensões, entre profundidades e até a dose de 50,0 $\mathrm{Mg} \mathrm{ha}^{-1}$ de biossólido, nos dois solos (Figura 1), corroborando com Jorge et al. (1991), que também não obtiveram alterações na retenção de água em Latossolo Vermelho argiloso nas tensões de 0,033 e $0,1 \mathrm{MPa}$, com a aplicação de $20,0 \mathrm{Mg} \mathrm{ha}^{-1}$ ano $^{-1}$ de lodo de esgoto, comparado à testemunha.

Segundo Beutler et al. (2002), a retenção de água no solo é influenciada pela matéria orgânica e, principalmente, pela densidade do solo. Com relação ao efeito da matéria orgânica, Centurion \& Andrioli (2000) concluíram que ela atuou de forma indireta na retenção de água, por meio da estrutura do solo quantificada pela densidade do solo. Nesse sentido, a redução na densidade do solo e o incremento no teor de matéria orgânica com a aplicação de biossólido não foram suficientes para alterar a curva de retenção de água no solo (Figura 1).

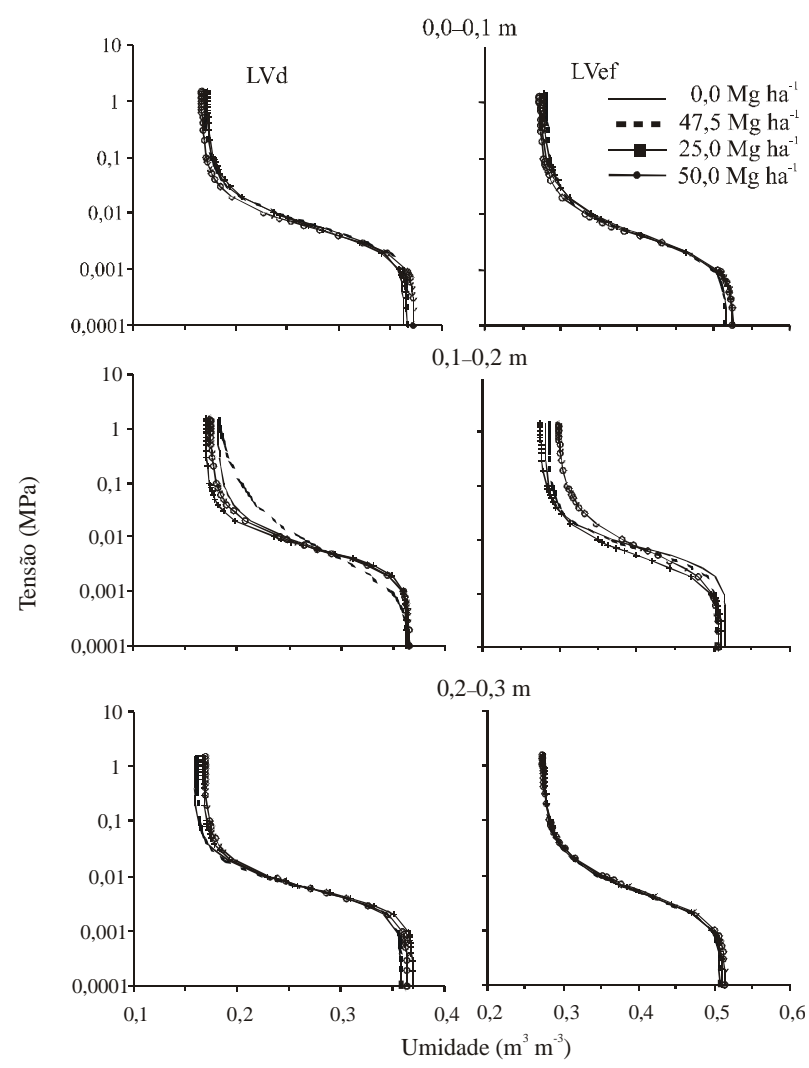

Figura 1. Curvas de retenção de água em diferentes doses de biossólido e camadas de Latossolo Vermelho distrófico, textura média (LVd), e Latossolo Vermelho eutroférrico argiloso (LVef).
Aggelides \& Londra (2000) verificaram incremento da retenção de água próximo a saturação com a aplicação de $75,0 \mathrm{Mg} \mathrm{ha}^{-1}$ de uma mistura de $62 \%$ de lixo doméstico, $21 \%$ de lodo de esgoto e $17 \%$ de serragem e incorporação até $0,15 \mathrm{~m}$ de profundidade, e Logan et al. (1996) verificaram incremento na retenção de água em solo de textura média com elevadas doses de lodo de esgoto, o que pode ser justificado por aumento no teor de matéria orgânica ou redução da densidade do solo mais expressivos que o verificado neste trabalho.

\section{Conclusões}

1. A macroporosidade é superior na camada de 0,0-0,1 m, a partir de 47,5 $\mathrm{Mg} \mathrm{ha}^{-1}$ e $50,0 \mathrm{Mg} \mathrm{ha}^{-1}$ de biossólido, no LVd e LVef, respectivamente.

2. A densidade do solo é inferior na dosagem de $50,0 \mathrm{Mg} \mathrm{ha}^{-1}$ no LVd de textura média, apenas na camada de $0,0-0,1 \mathrm{~m}$.

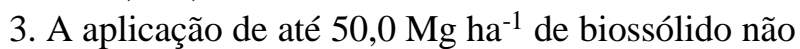
altera a porosidade total e a microporosidade nos dois solos.

4. A aplicação de 50,0 $\mathrm{Mg} \mathrm{ha}^{-1}$ de biossólido diminui a densidade do $\mathrm{LVd}$ em relação à testemunha e à dose de 25,0 $\mathrm{Mg} \mathrm{ha}^{-1}$.

5. A aplicação de biossólido aumenta o conteúdo de matéria orgânica dos dois solos apenas na camada de $0,0-0,1 \mathrm{~m}$, e não altera a retenção de água em todas as tensões tanto no LVd como no LVef.

6. Os efeitos do biossólido nos atributos físicos do solo dependem do tipo de solo e quantidade aplicada.

\section{Referências}

AGGELIDES, S.M.; LONDRA, P.A. Effects of compost produced from town wastes and sewage sludge on the physical properties of a loamy and clay soil. Bioresource Technology, v.71, p.253-259, 2000.

ALVES, W.L.; MELO, W.J.; FERREIRA, M.E. Efeito do composto de lixo urbano em um solo arenoso e em plantas de sorgo. Revista Brasileira de Ciência do Solo, v.23, p.729-736, 1999.

BERTOL, I. Degradação física do solo sob a cultura do alho. Revista Agropecuária Catarinense, v.2, p.47-50, 1989.

BEUTLER, A.N.; CENTURION, J.F.; SOUZA, Z.M.; ANDRIOLI, I.; ROQUE, C.G. Retenção de água em dois tipos de Latossolos sob diferentes usos. Revista Brasileira de Ciência do Solo, v.26, p.829-834, 2002.

BLAKE, G.R.; HARTGE, K.H. Bulk density. In: KLUTE, A. (Ed.). Methods of soil analysis. Madison: American Society of Agronomy, 1986. p.377-382. 
CENTURION, J.F; ANDRIOLI, I. Regime hídrico de alguns solos de Jaboticabal. Revista Brasileira de Ciência do Solo, v.24, p.701$709,2000$.

DANIELSON, R.E.; SUTHERLAND, P.L. Porosity. In: KLUTE, A. (Ed.). Methods of soil analysis. Madison: American Society of Agronomy, 1986. p.443-461.

DEBOSZ, K.; PETERSEN, S.O.; KURE, L.K.; AMBUS, P. Evaluating effects of sewage sludge and household compost on soil physical, chemical and microbiological properties. Applied and Soil and Ecology, v.19, p.237-248, 2002.

EMBRAPA. Centro Nacional de Pesquisa dos Solos (Rio de Janeiro, RJ). Manual de métodos de análise de solo. 2.ed. Rio de Janeiro, 1997. 212p.

FERREIRA, M.M.; FERNANDES, B.; CURI, N. Influência da mineralogia da fração argila nas propriedades físicas de latossolos da Região Sudeste do Brasil. Revista Brasileira de Ciência do Solo, v.23, p.515-524, 1999.

FURRER, O.J.; STAUFFER, W. Influence of sewage sludge application on physical properties of soils and its contribution to the humus balance. In: THE INFLUENCE of sewage sludge application on physical and biological properties of soils. Dordrecht: D. Reidel, 1983. p.65-74.

GENUCHTEN, M.T. van. A closed-form equation for predicting the hydraulic conductivity of unsaturated soils. Soil Science Society of America Journal, v.44, p.892-897, 1980.

GOLDSTEIN, N.; GLENN, J.; MADTES, C. Biosolids management update. Biocycle, v.39, p.69-72, 1998.

GONÇALVES, C.N.; CERETTA, C.A. Plantas de cobertura de solo antecedendo o milho e seu efeito sobre o carbono orgânico do solo, sob plantio direto. Revista Brasileira de Ciência do Solo, v.23, p.307-313, 1999.

JOFRE, J. Regrowth of faecal coliforms and salmonellae in stored biosolids and soil amended with biosolids. Water Science Technology, v.35, p.269-275, 1997.

JORGE, J.A.; CAMARGO, O.A.; VALADARES, J.M.A.S. Condições físicas de um Latossolo Vermelho-Escuro quatro anos após aplicação de lodo de esgoto e calcário. Revista Brasileira de Ciência do Solo, v.15, p.237-240, 1991.

KLUTE, A. Water retention: laboratory methods. In: KLUTE, A. (Ed.). Methods of soil analysis. $2^{\text {nd }}$ ed. Madison: American Society of Agronomy, 1986. pt. 1, p.635-662.

KUMAR, S.; MALLIK, R.S.; DAHIYA, I.S. Influence of different wastes upon water retention transmission and contact characteristics of sandy soil. Australian Journal of Soil Research, v.23, p.131-136, 1985 .

LINDSAY, B.J.; LOGAN, T.J. Field response of soil physical properties to sewage sludge. Journal of Environmental Quality, v.27, p.534-542, 1998 .

LOGAN, T.J.; HARRISON, B.J.; McAVOY, D.C.; GREFF, J.A. Effects of olestra in sewage sludge on soil physical properties. Journal of Environmental Quality, v.25, p.153-161, 1996.
MARCIANO, C.R.; MORAES, S.O.; OLIVEIRA, F.C.; MATTIAZZO, M.E. Efeito do lodo de esgoto e do composto de lixo urbano sobre a condutividade hidráulica de um Latossolo Amarelo saturado e não saturado. Revista Brasileira de Ciência do Solo, v.25, p.1-9, 2001.

MATHAN, K.K. Studies on the influence of long-term municipal sewage-effluent irrigation on soil physical properties. Bioresource Technology, v.48, p.275-276, 1994.

MELO, V.P. Propriedades químicas e disponibilidade de metais pesados para a cultura do milho em dois latossolos que receberam a adição de biossólido. 2002. 134p. Dissertação (Mestrado) - Universidade Estadual Paulista, Jaboticabal.

MELO, W.J.; MARQUES, M.O; MELO, V.P. O uso agrícola e as propriedades do solo. In: TSUTIYA, M.T.; COMPARINI, J.B.; ALEM SOBRINHO, P.; HESPANHOL, I.; CARVALHO, P. de C.T. de; MELFI, A.J.; MELO, W.J de; MARQUES, M.O. (Ed.). Biossólidos na agricultura. São Paulo: Companhia de Saneamento Básico do Estado de São Paulo, 2001. p.289-363.

METZGER, L.; YARON, B. Influence of sludge organic matter on soil physical properties. Advances in Soil Science, v.7, p.141$163,1987$.

NAVAS, A.; BERMÚDEZ, F.; MACHÍN, J. Influence of sewage sludge application on physical and chemical properties of Gypsisols. Geoderma, v.87, p.123-135, 1998.

ORTEGA, E.; NOGALES, R.; DELGADO, M. Modificación en la porosidad de un suelo por la adición de un compost de basura urbana. Anales de Edafología y Agrobiología, v.15, p.1735-1747, 1981.

PAGLIAI, M.; GUIDI, G.; LA MARCA, M.; GIACHETTI, M.; LUCAMANTE, G. Effects of sewage sludge and composts on soil porosity and aggregation. Journal of Environmental Quality, v.10, p.556-561, 1981.

REICHARDT, K. Capacidade de campo. Revista Brasileira de Ciência do Solo, v.12, p.211-216, 1988.

SILVA, J.E.; RESCK, D.V.S.; SHARMA, R.D. Alternativa agronômica para o biossólido produzido no Distrito Federal - I: efeito na produção de milho e na adição de metais pesados em latossolo no cerrado. Revista Brasileira de Ciência do Solo, v.26, p.487-495, 2002.

SILVA, J.E.; RESCK, D.V.S.; SHARMA, R.D.; FEITOZA, L. Utilização do lodo de esgoto como fonte de fósforo e nitrogênio para o milho. In: CONGRESSO BRASILEIRO DE CIÊNCIA DO SOLO, 26., 1997, Rio de Janeiro. Anais. Rio de Janeiro: Sociedade Brasileira de Ciência do Solo, 1997. 4p. CD-ROM.

SLOAN, J.J.; DOWDY, R.H.; DOLAN, M.S.; LINDEN, D.R. Long term effects of biosolids applications on heavy metal bioavailability in agricultural soils. Journal of Environmental Quality, v.26, p.966$975,1997$.

SORT, X.; ALCAÑIZ, J.M. Modification of soil porosity after application of sewage sludge. Soil \& Tillage Research, v.49, p.337$345,1999$.

Recebido em 31 de março de 2003 e aprovado em 12 de novembro de 2003 